\title{
IDENTIFIKASI JENIS LALAT BUAH (Bactrocera spp) DI GALELA KABUPATEN HALMAHERA UTARA DENGAN MENGGUNAKAN PERANGKAP METIL EUGENOL
}

\author{
Sunarno \\ Program Studi Agroteknologi, Fakultas Ilmu Alam dan Teknologi Rekayasa, Universitas Halmahera. \\ Kampus UNIERA Komplek GMIH Wari Ino Tobelo, Halmahera Utara, 97762 \\ Penulis Korespondensi Email : alexandersunarno@gmail.com
}

Diterima : 10 Maret 2016

Disetujui : 15 Juli 2016

\section{Intisari}

Kajian tentang Identifikasi Jenis Lalat Buah (Bactrocera spp) di Galela Kabupaten Halmahera Utara dengan menggunakan perangkap metil eugenol " dilakukan di daerah Galela, Kabupaten Halmahera Utara pada bulan Juli-Agustus 2014. Penelitian ini bertujuan untuk, mengetahui jenis lalat buah (Diptera : Tephritidae) dari Genus Bactrocera spp yang menyerang tanaman Hortikultura di Galela, Mengetahui jenis lalat buah dari Genus Bactrocera,spp yang dominan menyerang tanaman Hortikultura di Galela. Penelitian dilakukan dengan mengantungkan perangkap metil eugenol setinggi 1-1,5 m, sebanyak 18 perangkap pada selama 1 bulan. Dari penelitian yang telah dilakukan sampai pada pengamatan terakir pengamatan yang direncanakan di dapatkan hasil, untuk jumlah tangkapan lalat buah di Galela diperoleh yakni lalat buah sebanyak 6514 ekor, 7 jenis hama lalat buah yang paling dominan yakni B. carambolae (33\%), dan yang paling sedikit yakni B. curvifera (Walker $)(0,1 \%)$.

Kata Kunci : Bactrocera camabulae, Bactrocera curtivera, Galela, Metil eugenol, Lalat buah

\begin{abstract}
Studies on the Identification Type Fruit Fly (Bactrocera spp) in the Galela, North Halmahera by Using Methyl eugenol traps " made in the Galela, North Halmahera in the month of July-August 2014. This study aims to. Knowing the type of fruit flies (Diptera : tephritid) of the genus Bactrocera spp which attack plants Horticulture in the Galela, Knowing the type of the genus Bactrocera fruit flies, the dominant spp Hottikultura attack plants in the region Galela. The research was conducted by means of methyl eugenol trap pocket as high as 1-1.5 $\mathrm{m}, a$ total of 18 traps for 1 month. Results of research on fruit flies get caught in a trap in the area Galela, North Halmahera regency as many as 6714 birds. In the area there are 7 types Galela pest fruit flies is the most dominant B. carambolae (33\%), and is extensible at least B. curvifera (Walker) $(0.1 \%)$
\end{abstract}

Keywords : Fruit fly, Galela, Bactrocera camabulae, Bactrocera curtivera, Metil eugenol

\section{PENDAHULUAN}

Hama lalat buah (Bactrocera.spp) adalah hama yang merugikan. Berdasarkan tingkat kerusakan yang diakibatkan kerugian dapat mencapai Rp. 22 milyar per tahun. Salah satu jenis hama lalat buah yang paling banyak menimbulkan kerugian adalah Bactrocera dorsalis Hendel (Diptera; Tephritidae). Kerugian yang diakibatkan oleh hama tersebut dapat secara kualitatif dan kuantitatif (Kardinan, 2007).

Pemerintah Kabupaten Halmahara Utara mencanangkan program peningkatan kesejahteraan petani, salah satu program dari dinas pertanian adalah meningkatkan pendapatan petani dengan melalui bertanam tanaman hortikultura ( buah-buahan, sayuran dll), akan tetapi petani banyak mengalami hambatan karena kewalahan dalam penanganan hama penyakit.

Wilayah Galela terletak di bagian utara Kabupaten Halmahera Utara yang berjarak kurang lebih $50 \mathrm{Km}$ dari pusat kota Tobelo, yang pada tahun 1990 PT. Global, dan perusahaan pisang tersebut untuk bibitnya mendatangkan bibit isang dari Maluku akan tetapi setelah terjadinya perusahaan pisang tersebut tidak berjalan lagi dan lahan bekas perusahaan tersebut di manfaatkan oleh masyarakat sekitar untuk menanam berbagai tanaman hortikultura. Tanaman hortikultura yang ditanam pada wilayah 
Galela sangat banyak dan bervariasi seperti cabai, tomat, semangka, ketimun, pare, nangka, belimbing, mangga, pisang dan masih banyak jenis sayur-sayuran dan buah-buahan lainya, akan tetapi para petani yang berada pada wilayah tersebut mengeluhkan bahwa hasil dari tanaman hortikultuta khususnya buah-buahan dan sayursayuran yang ditanam kebanyakan sebelum masak sudah busuk dan terdapat ulat didalamnya.

Rendahnya hasil buah-buahan dan sayuran di wilayah tersebut disebabkan oleh serangan berbagai hama tanaman, salah satunya adalah serangan hama lalat buah yang menyerang tanaman tomat, cabe, ketimun, mangga, belimbing, pisang, nangka, cempedak, pare, ketimun dll. Masyarakat petani di wilayah Galela tersebut belum mengetahui tentang jenis lalat buah yang menyerang tanaman hortikultura dan pengendaliannya, selain itu juga selama ini belum pernah ada peneliti yang meneliti tentang jenis lalat buah yang ada di wilayah khususnya bekas lahan perusahaan pisang dan ada kemungkinan ada beberapa jenis lalat buah yang terbawa oleh bibit pisang yang berasal dari negara Korea tersebut.

Berdasarkan beberapa hal yang telah disejalaskan diatas, maka dapat dirumuskan permasalahan yakni:

a. Jenis lalat buah (Diptera : Tephritidae) Genus

Bactrocera apa saja yang menyerang tanaman hortikultura di Galela, Kabupaten Halmahera Utara?

b. Apa saja jenis lalat buah (Diptera : Tephritidae) Genus Bactrocera yang dominan menyerang tanaman hortikultura di Galela, Kabupaten Halmahera Utara?

Penelitian ini bertujuan untuk :

1. Mengetahui jenis lalat buah (Diptera : Tephritidae) dari Genus Bactrocera apa saja yang menyerang tanaman Hortikultura di Galela, Kabupaten Halmahera Utara.

2. Mengetahui jenis lalat buah (Diptera : Tephritidae dari Genus Bactrocera apa saja yang dominan menyerang tanaman Hottikultura di Galela, Kabupaten Halmahera Utara.

\section{METODE PENELITIAN}

Sebelum pelaksanaan penelitian dilaksanakan, perlu adanya persiapan agar dalam pelaksanaanya dapat berjalan dengan baik, persiapan penelitian ini meliputi persiapan : tempat penelitian, bahan dan alat, dan sebagainya yang dapat mendukung penelitihan ini. Pembuatan perangkap lalat buah dengan cara : 1 . Botol aqua dipotong tepat pada lekukan pertama dari ujung botol, 2 . Lobangi Botol aqua, usahakan seimbang bila digantung, 3. Masukkan kawat halus dan pada ujung kawat taruh kapas, 4. Tetesi kapas dengan atlabu (1 ml) dengan alat suntik, 5. Tetesi kapas dengan pestisida Regent (1ml) dengan alat suntik, 6. Perangkap siap digantung.

Bahan dan alat yang digunakan dalam penelitian merupakan bahan (Metil Eugenol Atlabu), Kapas, Regent ) dan alat (Botol Aqua, soldir, kawat, kater, gunting, suntikan, dll) dalam membuat perangkap maupun umpannya. Sehingga penelitian dapat berjalan lancar dari awal penelitian sampai akhir penelitian,

Penelitian dengan cara mengantungkan perangkap yang sudah siap digantung tersebut dengan ketinggian rata-rata $1 \mathrm{~m}$ sampai $1,5 \mathrm{~m}$ diatas permukaan tanah, , sebanyak 18 perangkap di wilayah Galela waktu pengantungan perang-kap pada pagi hari, dan pengambilan serangga lalat buah yang tertangkap oleh perangkap dilaksanakan pada setiap 1 minggu sekali dan penyuntikan atraktan Metil Eugenol setiap 2 minggu sekali

Pengamatan yang dilakukan adalah ketertarikan lalat buah pada Metil Eugenol, dengan cara mengamati dan menghitung lalat buah dari setiap perangkap yang menunjukan ketertarikan pada metil eugenol, Identifikasi beberapa spesies lalat buah, dengan cara mengidentifikasi secara morfologi beberapa spesies lalat buah yang berbeda yang tertangkap pada wilayah Galela. Dominansi jenis lalat buah dengan menghitung dan membandingkan dari beberapa jenis lalat buah yang tertangkap pada wilayah Galela, Analisis data menggunakan analisis diskriptif kualitatif untuk mengidentifikasi jenis lalat yang dominan di wilayah Galele Kabupaten halmahera Utara.

\section{HASIL DAN PEMBAHASAN}

\section{Hasil Tangkapan Lalat Buah di Galela}

Dari hasil perangkap ditemuakn paling banyak adalah pada perangkap nomor 6 sebanyak 782 ekor, dan paling sedikit adalah perangkap pada nomor 11 sebanyak 151 ekor. Hal ini di sebabkan karena pada perangkap nomor 6, dekat dengan tanaman buah-buahan seperti pisang, 
nangka, sukun, belimbing dan lain-lain. Pada perangkap nomor 11 jauh dari tanaman buahbahan, tetapi dekat dengan jeruk ikan dan jeruk nipis yang bukan merupakan inang dari hama lalat buah. Pada gambar 2, hasil tangkapan lalat buah yang paling banyak pada pengamatan ke-3 sebanyak 2469 ekor dan yang paling sedikit pada pengamatan ke-4 sebanyak 200 ekor.

Dari grafik pada gambar 2 menunjukan hasil tangkapan dari 18 perangkap sebanyak 6714 ekor, sedangkan pengamatan terakhir, yakni pengamatan ke-3 dapat menangkap lalat buah sebanyak 2469 ekor. Hal ini di sebabkan karena pada saat pengamatan ke-3 dilakukan penyun-tikan metil metil eugenol di lakukan setiap 2 minggu sekali. Hasil pengamatan yang`paling sedikit adalah pada pengamatan ke4 sebanyak 200 ekor Hal ini di sebabkan pada pengamatan ke-4 pengaruh bau metil eugenol sudah berku-rang dan populasi lalat buah di lapangan sudah banyak tertangkap sehingga berpengaruh terha-dap daya tarik lalat buah untuk masuk perang-kap.

Berdasarkan tabel 1 menunjukan bahwa ditemukan 7 jenis lalat buah yaitu: $B$. caramblae (Drew \& Hanocock), B. umbrosa Fabricius, B. papayae (Drew \& Hanocock), B. cucurbitae (Coquillet), B. musae (Tryon), B. curvifera (Walker), B.dorsalis (Hendel). Dimana dari 7 jenis lalat buah tersebut termasuk pada genus Bractocera, akan tetapi untuk Sub genusnya terdapat 2 yaitu Sub genus Bactrocera diantaranya lalat buah jenis : B. carambolae (Drew \& Hanocock), B. umbrosa Fabricius, B. papayae (Drew \& Hanocock), B. musae (Tryon), $B$. curvifera (Walker dan B. Dorsalis (Hendel), dan
Sub genus Zeugodacus yaitu lalat buah jenis $B$. cucurbitae (Coquillet).

Metil eugenol dapat menarik lalat buah yang masuk dalam genus Bactrocera. spp, akan tetapi tidak semua genus Bactrocera dapat di tarik oleh metil eugenol hanya genus Bactrocera sub genus Bactrocera , Muryati (2007) menyatakan bahwa sebagian jenis lalat buah sub genus Zeugodacus juga tertarik pada metil eugenol dan cure lure seperti pada lalat buah B.cucurbitae. Berdasarkan hasil tangkapan yang diperoleh diketahui bahwa pada semua perangkap model steiner yang diberi metil eugenol dapat menangkap 7 jenis lalat buah yaitu $B$. caramblae (Drew \& Hanocock), B. umbrosa Fabricius, B. papayae (Drew \& Hanocock), B. cucurbitae (Coquillet), B. musae (Tryon), B. curvifera (Walker), B.dorsalis (Hendel). Hal ini disebabkan karena lalat buah jenis B. Carambo-lae merupakan hama penting pada tanaman yang sedang berbuah. Hal ini sesuai dengan pernyataan Sunarno, (2011) bahwa jenis B. carambolae menyerang berbagai macam buah-buahan sebagai inangnya dan merupakan hama penting pada tanaman belimbing. Lalat buah B. Papayae merupakan hama utama pada tanaman pepaya dan di sekitar lokasi ditemukan buah pepaya yang sedang berbuah. B. umbrosa dikenal sebagai lalat nangka karena banyak menyerang dan ditemukan pada tanaman nangka hal ini sesuai dengan pernyataan yang di ungkapkan oleh Nugroho (2001) bahwa $B$. umbrosa juga disebut sebagai lalat buah nangka. $B$. papayae merupakan hama utama pada pepaya. Lalat buah B. cucurbitae, merupakan lalat buah yang banyak pada tanaman cucurbitae seperti Melon, Semangka, Pare, dan

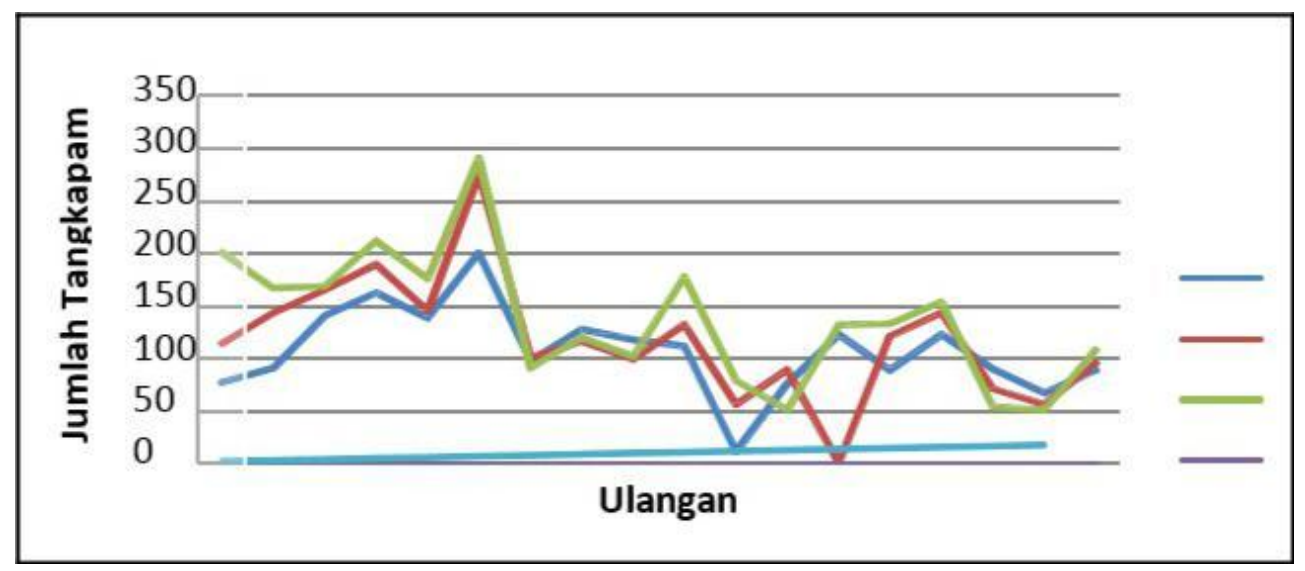

Gambar 1. Hasil tangkapan lalat buah di wilayah Galela 


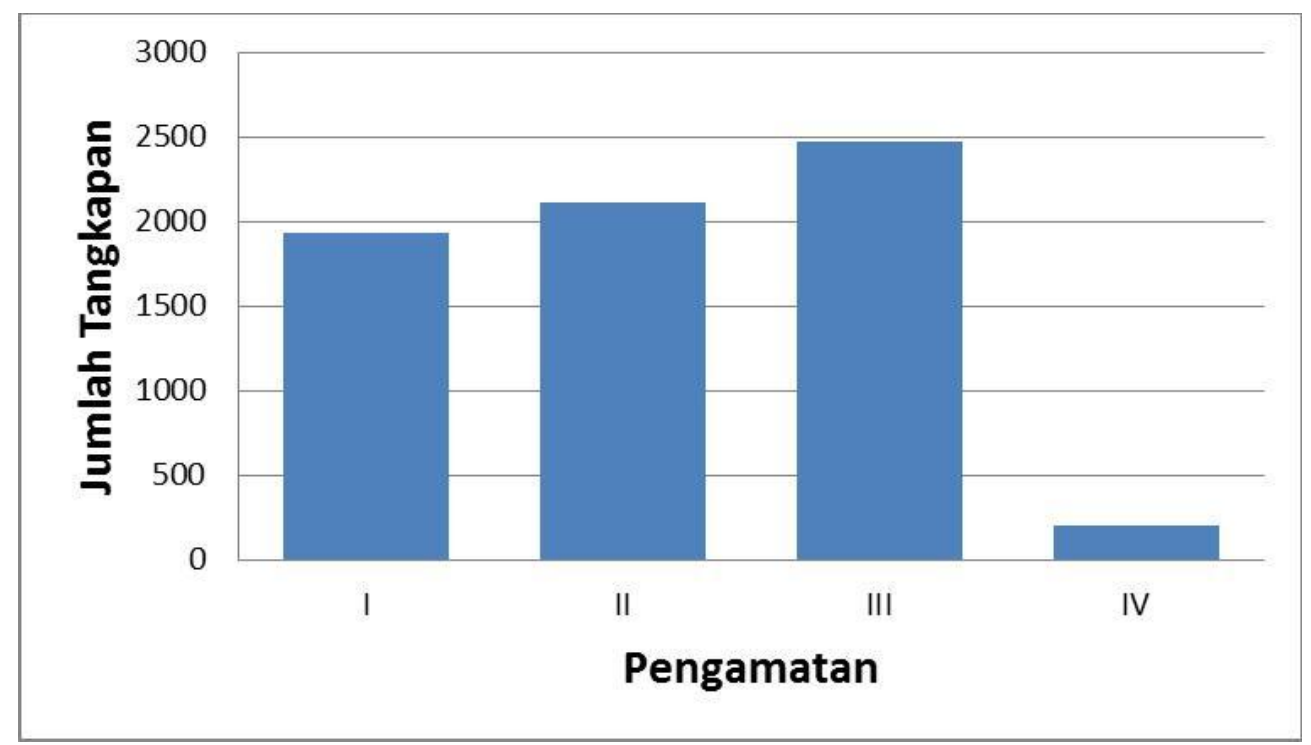

Gambar. 2. Grafik jumlah tangkapan berdasarkan pengamatan di daerah Galela

Tabel. 1. Jenis Lalat Buah Terperangkap pada Perangkap di daerah Galela

\begin{tabular}{clll}
\hline Nomor & \multicolumn{1}{c}{ Jenis Lalat Buah } & Genus & Sub Genus \\
\hline 1 & B. carambolae (Drew \& Hanocock) & Bactrocera & Bactrocera \\
\hline 2 & B. umbrosa Fabricius & Bactrocera & Bactrocera \\
\hline 3 & B. papayae (Drew \& Hanocock) & Bactrocera & Bactrocera \\
\hline 4 & B. cucurbitae (Coquillet) & Bactrocera & Zeugodacus \\
\hline 5 & B. musae (Tryon) & Bactrocera & Bactrocera \\
\hline 6 & B. curvifera (Walker) & Bactrocera & Bactrocera \\
\hline 7 & B. dorsalis & Bactrocera & Bactrocera \\
\hline
\end{tabular}

Metimun. Lalat buah jenis B. musae merupakan hama penting pada tanaman pisang Daerah Kabupaten Halmahera Utara Galela merupakan daerah yang banyak menghasilkan tanaman pisang, Siwi dkk, (2006) bahwa lalat bauah jenis B. Musae merupakan lalat buah penting yang menyerang pada tanaman pisang. B. curvifera (Walker), merupakan hama penting pada berbagai tanaman seperti pada tanaman kluwih, sukun dan cempedak. Di sekitar lokasi penelitian banyak terdapat tanaman seperti sukun dan cempedak sehingga lalat buah jenis B.curvifera

berasal sekeliling tempat penelitian karena metil eugenol dapat menarik lalat buah untuk masuk ke perangkap sampai maksimal $2 \mathrm{~km}$ dan daerah penyebaranya di, Maluku utara, hal ini sesuai dengan pernyataan yang diungkapkan oleh Siwi dkk, (2006), bahwa metil eugenol dapat menarik lalat buah sampai pada jarak $2 \mathrm{~km}$ dari perangkap dan daerah penyebarannya di Timika, Fak-fak, Merauke, dan Maluku utara B. Dorsalis
(Hendel), yang terperangkap merupakan lalat buah yang banyak menyerang pada tanaman cabai merah, tomat, jeruk, pisang raja, dan pisang susu, karena di lahan penelitian adalah tanaman pisang raja dan pisang susu banyak terdapat di sekeliling tempat penelitian sehingga lalat buah B.dorsalis banyak terdapat di daerah Galela karena inangnya tersedia, hal ini sesuai dengan pernyataan yang di ungkapkan oleh (Deptan, 2008), bahwa menurut pemantauan yang dilakukan oleh pusat karantina pertanian Jakarta sasaran utama serangan lalat buah $B$. dorsalis, antara lain belimbing manis, jambu air, jambu biji, mangga, nangka,semangka, melon dan cabai, jeruk manis, pisang.

\section{Jenis Lalat Buah yang Dominan di Galela}

Dari gambar di bawah ini menunjukan bahwa jenis lalat buah paling banyak adalah $B$. carambolae dari 7 jenis lalat buah yang tertangkap pada perangkap dengan prosentase 




Gambar. 3. Jenis Lalat Buah di Daerah Galela

(33\%), B. musae (Tryon)(28\%), B. papayae (Drew \& Hanocock) (20\%), B. umbrosa Fabricius (18\%), B. dorsalis (1,2\%), B. cucurbitae (Coquillet) (0,1\%), dan B. curvifera (Walker) $(0,1 \%)$.

Pada Gambar 3. menunjukkan bahwa populasi lalat buah dari jenis $B$. carambolae merupakan lalat buah yang paling dominan di daerah Galela, Halmahera Utara sebesar $33 \%$, dan yang paling sedikit adalah jenis lalat buah B.curvifera sebanyak 9 ekor atau $0,1 \%$. Lalat buah $B$. carambolae merupakan lalat buah yang preferensinya paling tinggi terhadap atraktan metil eugenol bila dibandingkan dengan lalat buah jenis yang lainnya, hal ini sesuai dengan penelitian yang dilakukan oleh Muryanti dkk, (2008) yang menyatakan bahwa lalat buah jenis B. carambolae yang preferensinya lebih tinggi terhadap atraktan metil eugenol yaitu $100 \%$. Lalat buah $B$. carambolae merupakan lalat buah yang banyak mempunyai inang. Pada lokasi penelitian yang berada di dalam lokasi daerah Kao Barat, banyak sekali tanaman yang mejadi inang dari lalat buah jenis B.carambolae misalnya, mangga, cabe kriting, rambuatan, belimbing, tomat, nangka, pepaya dll, hal ini yang menyebabkan lalat buah B.carambolae merupakan lalat buah yang paling dominan di daerah Galela Halmahera Utara.

Sedangkan jens lalat buah yang paling sedikit adalah jenis B. curvifera (Walker), merupakan hama penting pada berbagai tanaman seperti pada tanaman kluwih, sukun dan cempedak. Di sekitar lokasi penelitian banyak terdapat tanaman seperti sukun dan cempedak sehingga lalat buah jenis B.curvifera berasal sekeliling tempat penelitian karena metil eugenol dapat menarik lalat buah untuk masuk ke perangkap sampai maksimal $2 \mathrm{~km}$ akan tetapi populasinya masiih sedikit dan daerah penyeba-ranya di, Maluku utara, hal ini sesuai dengan pernyataan yang diungkapkan oleh Siwi dkk, (2006) bahwa metil eugenol dapat menarik lalat buah sampai pada jarak $2 \mathrm{~km}$ dari perangkap dan daerah penyebarannya di Timika, Fak-fak, Merauke, dan Maluku utara

Dari penelitian ini yang lakukan peneliti selama 2 tahun ni yaitu tahun 2013 dan tahun 2014 dapat di simpulkan bahwa sebaran jenis hama lalat buah yang berada di daerah Kabupaten Halmahera Utara secara keseluruhan terdapat 8 jenis, dimana di daerah Kao terdapat 7 jenis yaitu B. carambolae (Drew \& Hanocock), B. umbrosa Fabricius, B. papayae (Drew \& Hanocock), B. cucurbitae (Coquillet), B. musae (Tryon), B. curvifera (Walker), B.dorsalis (Hendel)., di Daerah Galela terdapat 7 jenis hama lalat buah yaitu , B. carambolae (Drew \& Hanocock), B. umbrosa Fabricius, B. papayae (Drew \& Hanocock), B. cucurbitae (Coquillet), B. musae (Tryon), B. curvifera (Walker), B.dorsalis (Hendel), dan di daerah Tobelo terdapat 8 jenis hama lalat yaitu yaitu $B$. carambolae (Drew \& Hanocock), $B$. 
umbrosa Fabricius, B. papayae (Drew \& Hanocock), B. cucurbitae (Coquillet), B. musae (Tryon), B. curivera (Walker), B.dorsalis (Hendel) dan B. Bryonae.

\section{KESIMPULAN}

Kesimpulan dari hasil penelitian ini adalah :

1. Lalat buah yang terperangkap dalam perangkap di daerah Galela, yaitu sebanyak 6714 ekor.yang paling banyak adalah pada perangkap nomor 6 sebanyak 782 ekor dan paling sedikit adalah perangkap pada nomor 11 sebanyak 151 ekor.

2. Di daerah Galela terdapat 7 jenis hama lalat buah yang paling dominan adalah $B$. carambolae $(33 \%)$, dan yang paling sedikit adalah $B$. curvifera (Walker) $(0,1 \%)$.

\section{DAFTAR PUSTAKA}

, dan Steven Popoko, 2013. Keragaman Jenis Lalat Buah (Bactrocera spp) di Tobelo, Halmahera Utara. Jurnal Agroforestri VIII, Nomor 4. Politeknik Perdamaian Halmahera Tobelo

Direktorat Perlindungan Tanaman Hortikultura, 2008 Pengenalan Dan Pengendalian Penyakit Hortikultura Prioritas. Direktorat jendral Hortikultura.Jakarta

Herlinda.S. Zuroaidah, Yulia Pujiastuti, Sunar Samad, dan Triani Adam, 2007. Spesies Lalat Buah yang Menyerang Sayuran Solanaceae dan Cucurbitaceae di Sumatera Selatan, Stasiun Karantina Kelas II Merak.

Kardinan.A. 2007 Atraktan Nabati untuk Mengendalikan Lalat Buah Pada Pertanian Organik. Balai Penelitian Tanaman Rempah dan Obat. Bogor

Muryati, A. Hasyim, dan Riska. 2007. Preferensi Spesies Lalat Buah terhadap Atraktan Metil Eugenol dan Cue-Lure dan Populasinya di Sumatera Barat dan Riau .Balai Penelitian Tanaman Buah Tropika Solok

Nugroho, 2001. Pengaruh Kepadatan Terna dan Lama Penyulingan terhadap Rendemen dan Karakteristik Minyak Melaleuca bracteata. Jurnal LITTRI Vol.7 No.4

Siwi, Purnama Hidayat dan Suputa 2006. Taksonomi dan Bioekologi Lalat Buah

Penting di Indonesia (Diptera: Tephritidae) Kerjasama Balai Besar Peneltian dan Pengembangan Bioteknologi dan Sumberdaya Genetik Pertanian dengan Departement of Agriculture, Fisheries and Forestry Australia

Sunarno. 2011. Keterarikan lalat buah (Bactro-cera,spp) terhadap perangkap dan umpan berwarna. Tesis, Ugm. Yogyakarta 